\title{
An overview of the immunopathology of human paracoccidioidomycosis
}

\author{
Gil Benard
}

Received: 18 May 2007/Accepted: 18 September 2007

(C) Springer Science+Business Media B.V. 2007

\begin{abstract}
We review here the advances in the understanding of the immunopathology of human paracoccidioidomycosis (PCM). Its investigation must take in account the intriguing natural history of the mycosis and its agent, providing clues to the mechanisms that lead to development of disease (unbalanced host-parasite relationship?) or to the clinically silent, chronic carrier state (balanced hostparasite relationship?), in exposed people living in endemic areas. Although the literature on this subject has progressed notably, the overall picture of what are the mechanisms of susceptibility or resistance continues to be fragmentary. Major advances were seen in the description of both the cytokines/chemokines associated to the different outcomes of the hostparasite interaction, and the fungus-monocyte/macrophage interaction, and cytokines released thereof by these cells. However, relatively few studies have attempted to modify, even in vitro, the patients' unbalanced immune reactivity. Consequently, the benefits of this improved knowledge did not yet reach clinical practice. Fortunately, the previous notion of the immune system as having two nearly independent arms, the innate and adaptive immunities, leaving a
\end{abstract}

G. Benard $(\bowtie)$

Laboratory of Dermatology and Immunodeficiencies (LIM-56), Medical School of the University of São Paulo, Av. Dr. Enéas de Carvalho Aguiar $5003^{\circ}$. floor,

Sao Paulo, Brazil

e-mail: mahong@usp.br large gap between them, is now being overcome. Immunologists are now trying to dissect the connections between these two arms. This will certainly lead to more productive results. Current investigations should address the innate immunity events that trigger the IL-12/IFN- $\gamma$ axis and confer protection against PCM in those individuals living in endemic areas, who have been infected, but did not develop the mycosis.

Keywords Paracoccidioidomycosis . Paracoccidioides brasiliensis · Human immunology · Cytokines · T-cell $\cdot$ Immunesuppression ·

Macrophages

\section{The problem}

The investigation of the immunopathology of paracoccidioidomycosis (PCM) should be addressed taking in account the intriguing natural history of the mycosis and its agent. First, the fact that most likely humans are accidentally infected, with no evidence up to now that $P$. brasiliensis $(\mathrm{Pb})$ may acquire any upgrade in its adaptive abilities by infecting the mammalian host. This may be related to the observed absence of inter-human transmission of the yeast. Second, the possibility that the yeast would be released from the host back to the environment with a somewhat improved ability to out-compete other microorganisms has not yet been documented. On the contrary, it appears that infecting the living 
host represents a dead alley for the fungus [1]. With this in mind, what then dictates the events that lead to disease development (unbalanced host-parasite relationship?) or to clinically silent, chronic carrier state (balanced host-parasite relationship?), in exposed people living in endemic areas? It should be remembered that the latter situation is the rule, since the great majority of the individuals living in endemic areas will never develop the mycosis. Although there are no well-conducted epidemiological studies, the risk of developing disease after $P$. brasiliensis infection is much lower than that after acquiring $M$. tuberculosis infection, the agent of a chronic granulomatous disease also endemic in many areas of Latin America, which is up to $5-10 \%$ during lifetime of those infected [2]. This suggests that potential virulence factors or fungal strategies that may optimize yeast survival within the human host cannot not be envisaged as the result of a selective pressure from the mammalian host environment. The highinfected subjects/patients ratio even in highly endemic areas is in agreement with this notion.

It is assumed that the acute/subacute form of the disease would represent a continuum from the initial infection, with short incubation times (weeks or few months, few years?), while the chronic form of the disease would be the consequence of reactivation of the fungus from quiescent foci [3]. One would affect younger subjects, typically under 30-years-old, while the other would be characteristic of older ( $>30$ years) adult persons. However, this age distinction may merely reflect epidemiological characteristic associated with the type of clinical manifestation [4, 5]. Those who work at clinical mycology services in endemic areas have eventually had the opportunity to diagnose acute/subacute PCM in older individuals, and the typical chronic form of the disease in patients younger than 30-years-old. Moreover, there are subacute cases in which the incubation time has apparently lasted for years and not months [6].

That the natural history of the mycosis, on the other hand, is intimately related to the immune status of the patient is demonstrated by the frequent difficulty in classifying the clinical presentation of the mycosis of persons with AIDS [7]. In many cases, it likely represents an illness resulting from reactivation of the yeast from quiescent foci. However, clinically, the resemblance is with an acute form of the disease. Thus, reactivation of the yeast, which in the non-immunosuppressed usually results in the typical involvement of lungs and other sites of the respiratory tract, in immunosuppressed subjects leads to a disseminated disease similar to the acute form. Such atypical presentation had been described long ago in patients with malignancies by professor C. S. Lacaz [8]. This presentation was coined opportunistic or mixed form (Fig. 1) [7].

How immunopathological studies may help us better understand the mechanisms that underlie the variability in the outcomes of the host- $P$. brasiliensis relationship? Unfortunately, the investigations addressing this topic, specially in humans, the focus of this review, have been mostly merely descriptive, focusing mainly the cellular aspects of immune responses, and reproducing much of what have previously been done in other, better studied, chronic granulomatous infections either of fungal etiology or not. Few researchers attempted to modulate in vitro these immune responses in order to characterize more precisely the most relevant or dominant mechanisms.
Fig. 1 Overview of the natural history of the hostparasite interaction in human paracoccidioidomycosis

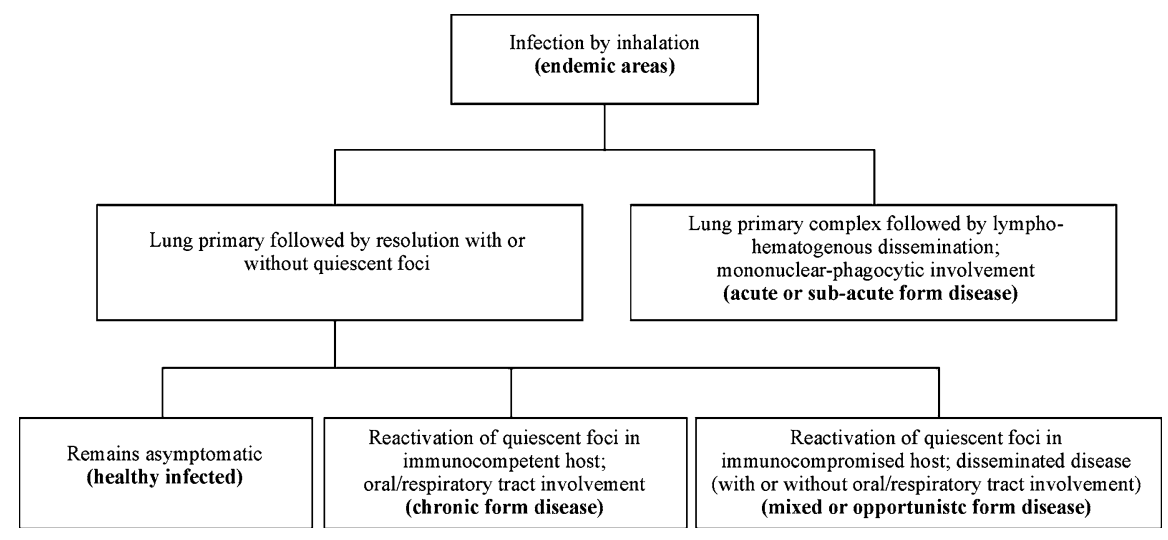


A number of groups, including ours, have shown that immune reactivity differs among healthy exposed individuals, patients with the chronic form of the disease, patients with the acute/subacute form of the disease, and individuals who have been cured of the mycosis. On the other hand, the mechanisms of adhesion, invasion and survival within host cells, leading to the establishment of productive infection have recently been explored in depth, and are discussed elsewhere in this issue.

\section{Immunological description: the lymphoproliferative response, the cytokine balance and the monocytes}

Studies published mainly in the 1970s and 1980s have shown depressed cellular immune responses of PCM patients, usually employing the lymphocyte proliferation and/or leukocyte migration inhibition tests [9-16]. They have shown that the cellular arm of the immune responses is affected both in a specific (elicited by $P$. brasiliensis components) and a nonspecific fashion (elicited by microbial antigens other than $\mathrm{Pb}$ or mitogens). Quantification of the circulating subsets of mononuclear cells generally showed only modest or even absence of abnormalities [17]. In fact, later in situ studies showed that most of these cell subsets were well represented within the lesions, either forming a palisade around or permeating the granulomatous lesions [18]. The gradual modifications in the cellular infiltrative pattern along with the initiation of anti-fungal treatment have recently been described, starting from the exuberant inflammatory process up to the initiation of the fibrosis and healing process [18].

To address the apparent paradox between the finding of a pronounced deficit of lymphocyte proliferative responses to mitogens and antigens from microbes other than $\mathrm{Pb}$, which could denote a more generalized impairment of the cellular immunity of PCM patients, and the clinical observation that PCM patient are not more prone to acquire other infectious diseases (with the exception of the probably overestimated [20] association with pulmonary TB), we focused our studies on the immune responses to more specific $\mathrm{Pb}$ antigens. These studies showed that the nature of the cellular immune defect was predominantly antigen-specific [21, 22]. Decreased immune responses to challenges with $\mathrm{Pb}$-unrelated microbial antigens were probably a consequence of the impairment of the general status of the patients, instead of an intrinsic defect of the immunity of PCM patients $[14,16]$. In disagreement with some studies, but in agreement with others, we observed that the majority of the patients with PCM presented overall adequate $\mathrm{T}$ cell responses to mitogens (and to a $\mathrm{Pb}$-unrelated fungal antigen). These studies are summarized in Table 1 [9-16, 21-26].

Later on, on the basis of increasing amount of information regarding the cytokines and chemokines that regulate the differentiation of cellular immune responses and the description of patterns of immune responses associated with defined enhanced/ depressed cytokine and chemokine expression, several studies have then sought to associate these patterns with the different outcomes of the Pb-human host interaction. PCM itself revealed to be a quite good example of how the concept of cytokineregulated patterns of immune responses could be applied to the study of the immune-regulation taking place in chronic granulomatous infectious diseases. Several groups addressed this question by quantifying the cytokines released in vitro from patients' cells. The results published so far were, in general, quite concordant and the picture that emerged were quite consistent, as depicted in Table 2 [19, 25, 27-34]. In brief, these studies showed that the acute/subacute form of the disease is associated with down modulation of the Th- 1 cytokine pattern and expression of a dominant Th-2 immunity consisting of high levels of a subset of cytokines such as IL-4, IL-5 and IL-10, specific antibodies of the IgE and IgG4 subclasses, in situ and peripheral blood eosinophilia, among other parameters. Those with the chronic form of the disease similarly presented a trend to downmodulated Th-1 type responses, but polarization toward Th-2 reactivity was infrequently seen. Importantly, in some studies, it was reported that reactivity of the healthy infected controls could be distinguished from that of patients. A schematic view summarizing these findings is shown in Fig. 2.

The cytokine balance also strongly affects diverse macrophage activities; these cells, in turn, have the ability to secrete a large array of pro and antiinflammatory cytokines that certainly interfere with the regulation of the pattern of immune reactivity to the invading agent. Cells of the macrophage/monocyte lineage (and pulmonary dendritic cells, according 
Table 1 Published studies evaluating the lymphocyte proliferative responses of paracoccidioidomycosis patients as compared to controls

\begin{tabular}{|c|c|c|c|c|}
\hline \multirow[b]{2}{*}{ Ref. (Year) } & \multirow[b]{2}{*}{ Population studied $(n)$} & \multicolumn{3}{|c|}{ Lymphocyte proliferative responses to } \\
\hline & & Mitogen & $\mathrm{PbAg}$ & Other $\mathrm{Ag}$ \\
\hline $9(1971)$ & Pt: 10 ; Co: $10 \mathrm{NS}$ & $4 \mathrm{nl}, 6 \downarrow$ & ND & ND \\
\hline $10(1976)$ & Pt: 13 CF, 6 AF; Co: 40 NS & $8 \mathrm{nl}, 11 \downarrow$ & $12 \downarrow, 6 \mathrm{nl}^{\mathrm{a}}$ & $5 \mathrm{nl}, 9 \downarrow$ \\
\hline $11(1977)$ & Pt: 17 ; Co: 59 NS, 18 treated & $14 \mathrm{nl}, 3 \downarrow$ & $\downarrow$ or $\mathrm{nl}^{\mathrm{b}}$ & $\mathrm{nl}$ \\
\hline $12(1978)$ & Pt: 16 ; Co: 16 NS, 16 treated & $\downarrow$ & $\downarrow$ & ND \\
\hline $13(1982)$ & Pt: 3 CMF, 4 CLF, 3 AF; Co: 10 treated, 8 NS(?) & $\downarrow$ & $\downarrow$ & $\downarrow$ \\
\hline $14(1983)$ & Pt: 16 CLF, 10 AF; Co: 25 NS & $16 \downarrow 10 \mathrm{nl}$ & ND & ND \\
\hline $15(1985)$ & Pt: 9 AF, 30 CMF, 8 CLF; Co: 27 NS & $\begin{array}{l}8 \downarrow, 9 \mathrm{AF} \\
22 \downarrow, 30 \mathrm{CMF} \\
5 \downarrow, \mathrm{CLF}\end{array}$ & $\downarrow$ or $\mathrm{nl}$ & ND \\
\hline $16(1989)$ & Pt: 28 CF; Co: $21,18 \mathrm{NS}$ & $\begin{array}{l}\text { PHA: } 16 \mathrm{nl}, 11 \downarrow \downarrow \text { PWM: nl } \\
\text { ConA } 16 \mathrm{nl}, 11 \downarrow\end{array}$ & $7 \mathrm{nl}, 10 \downarrow$ & ND \\
\hline $21(1996)$ & Pt: 10 AF, 22 CF; Co: 155, 15 NS & $\mathrm{Nl}$ & $\downarrow$ & $\mathrm{nl}$ \\
\hline $22(1997)$ & Pt: 5 AF, 5 CLF, 10 CMF; Co: 12 NS, $12 \mathrm{~S}$ & $\mathrm{Nl}$ & $\begin{array}{l}\text { CMF } \downarrow \text { AF } \downarrow \\
\text { CLF nl or } \downarrow\end{array}$ & $\mathrm{nl}$ \\
\hline 23 (1999) & Pt: 45; Co: 32 NS & $\downarrow$ & ND & ND \\
\hline 24 (1999) & Pt: 8 AF; Co: $4 \mathrm{~S}, 12$ treated, 4 NS & ND & $\downarrow$ & ND \\
\hline $25(2002)$ & Pt: AF 14 CMF; Co: 23 NS, 19 S & ND & $\downarrow$ & ND \\
\hline $26(2003)$ & Pt: 20 CLF; Co: 15 NS & $\downarrow$ & $\downarrow$ or $\mathrm{nl}^{\mathrm{a}}$ & ND \\
\hline
\end{tabular}

PbAg: P. brasiliensis antigen; mitogen: PHA, Con A or PWM; Pt: Patients; Co: Controls; NS: not sensitized to P. brasiliensis antigens; S: sensitized to $P$. brasiliensis antigens; Treated: patients treated and on clinical remission; CF: chronic form; CMF chronic multifocal form; CLF chronic localized form; AF: acute form, nl: similar to controls

${ }^{a} \mathrm{PbAg}$ suitability for measuring lymphocyte proliferative responses was not tested with a responder control group

b $\mathrm{PbAg}$ elicited low LPR in the positive control group (treated patients)

to studies in experimental models [35]), are in a privileged position to exert their defensive and regulatory abilities. They are most likely among the first ones to interact with the fungus (either recently inhaled conidia or the ensuing, transformed yeast cells). Their digestive and killing abilities, along with the cytokines secreted in response to this challenge, will be crucial to the subsequent events and, ultimately, to the fate of the infectious process. In fact, macrophages are considered central to the anti-Pb immunity [36]. Neutrophil accumulation has been described in the early phase of the immune response, either permeating the granulomatous reaction or forming microabscesses within them [37-40]. These cells have been shown to also exert in vitro anti- $\mathrm{Pb}$ activity [41-44], but their in vivo role in the host defense against the fungus remains to be determined.

In fact, we have described the existence of a dichotomy between IL-10 and IL-12p70 (the bioactive form of this cytokine) secretion in PCM patients. Their monocytes preferentially release IL-10 both without exogenous stimulation and when challenged in vitro with the $P$. brasiliensis main antigenic component, the $43 \mathrm{kDa}$ glycoprotein, or with LPS $[19,29,32]$. Little or no IL-12p70 was released [Romano CC, Mendes-Giannini MJS, and Benard G, unpublished data]. On the other hand, monocytes from healthy donors who have been cured of PCM or have been infected, but remained asymptomatic, released large amounts of IL-12p70 and little IL-10. Recently high levels of IL-18 were also demonstrated in the sera of patients [45]. Elegant experimental PCM studies (Lenzi HL and Restrepo A, unpublished data) have shown macrophages with engulfed, gemulating $\mathrm{Pb}$ yeast cells trafficking in the lymphatic system. Thus macrophages have a dual role in PCM: they can either be instrumental to dissemination of the infection or to its containment. In both cases, they 


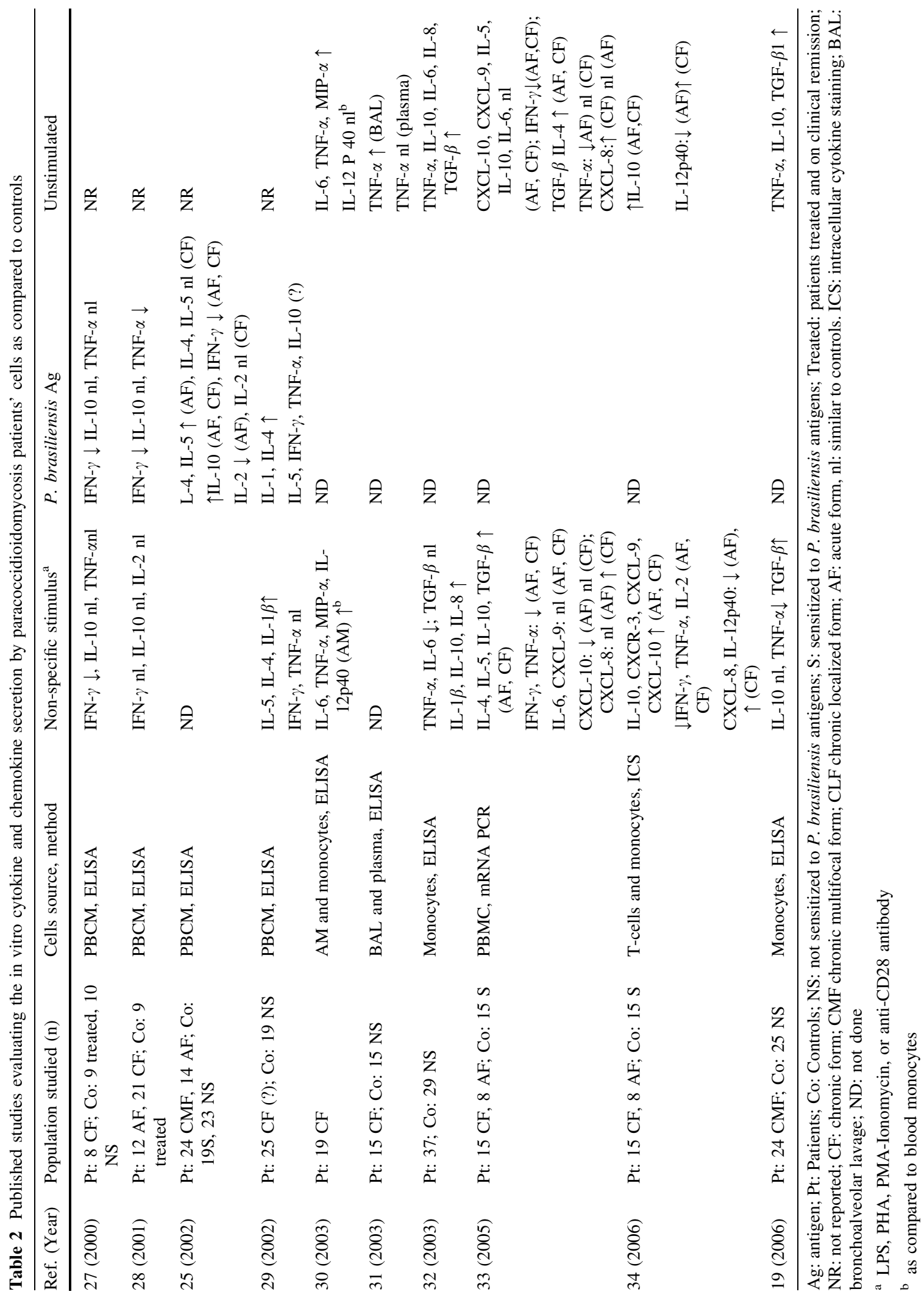


Fig. 2 Overview of the cytokine regulation associated with the three main outcomes of the $P$. brasiliensis-human host interaction, based on data on the immune responses to the immunodominant antigenic component of the yeast, the $43 \mathrm{kDa}$ glycoprotein (gp43). $\mathrm{Pb}$,

Paracoccidioides brasiliensis; МØ, macrophage; IL, interleukin; IL-12R, IL-12 receptor; $\beta 1$ and $\beta 2$, subunits of the IL-12R; necrosis factor, STAT, signal transducers and activators of transcription IFN, interferon; TNF, tumor

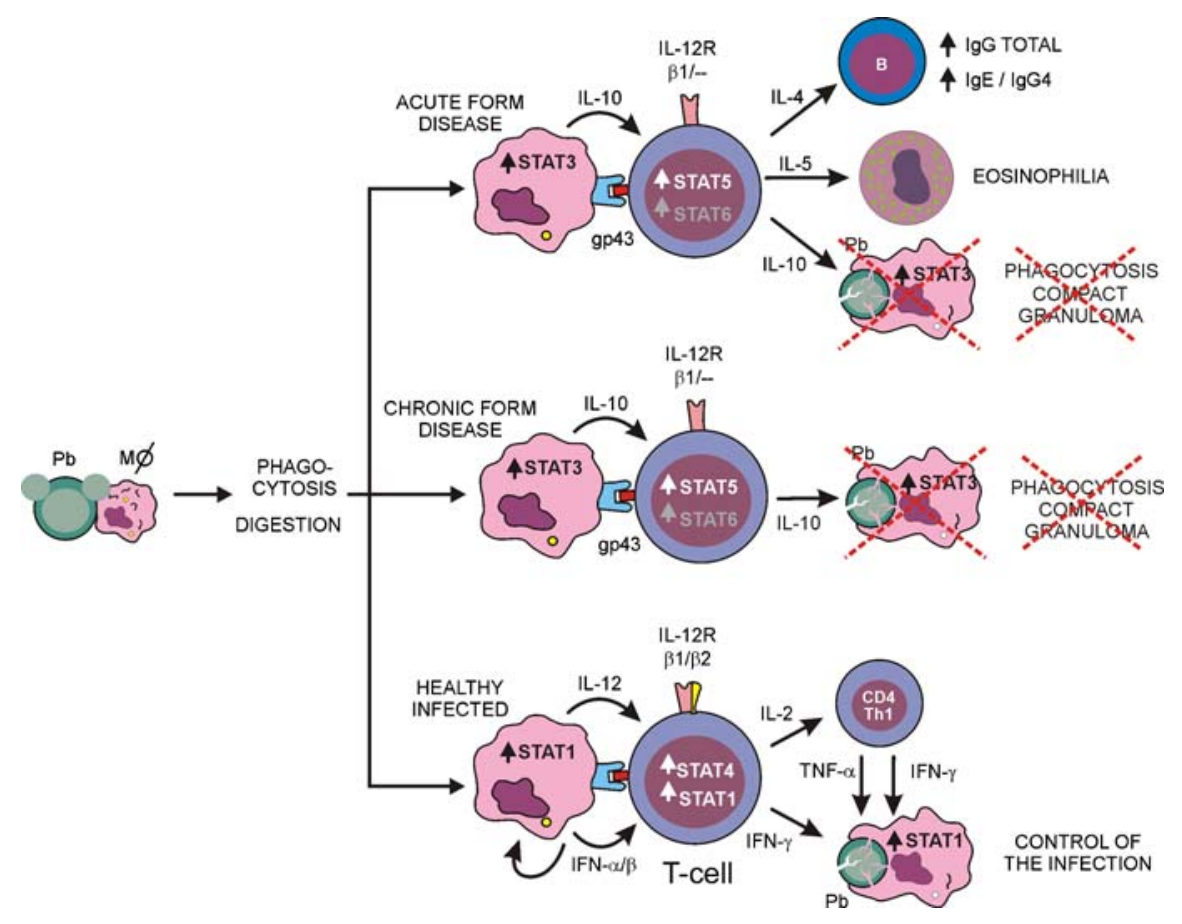

are critical to the outcome of the infection. The cytokine balance certainly plays a role in this "decision": adequate macrophage activation would be needed to increase its anti-fungal properties as suggested by the observation that macrophages from healthy donors exhibit very limited in vitro activity against virulent $\mathrm{Pb}$ strains ( $\leq 5 \%$ reduction in the number of $\mathrm{CFU}$ ), as compared to less virulent strains $[31,46]$. In fact, macrophages isolated from patients' peripheral blood exhibited slightly higher, but still weak in vitro killing capacity against virulent $\mathrm{Pb}$ (only $\sim 10-15 \%$ reduction in the number of CFU) $[31,46]$. This slight enhancement was accounted for the more activated status of patients' cells due to their previous, in vivo, exposure to fungal antigens. Of note, these data were obtained with a high (50:1) macrophage to yeast cell ratio, and concurrent experiments using $C$. albicans yeast forms as target revealed higher fungicidal activity. Thus, while macrophages that have been challenged with $\mathrm{Pb}$ or its components release a modified repertoire of cytokines, which regulates the subsequent adaptive immunity, they in turn depend on a positive feedback of the adaptive immunity, signaled through the release of cell-activating factors, to achieve the required stronger anti- $\mathrm{Pb}$ activity. Differently from experimental PCM, where non-oxidative mechanisms were shown to account for the killing activity of activated macrophages, in humans, products generated by the oxidative burst (e.g., $\mathrm{H}_{2} \mathrm{O}_{2}$ ) seem to play a major role [47]. More recently, however, IL-15 was shown to enhance $P$. brasiliensis killing by macrophages by a mechanism that was independent of oxidative burst products [48]. Other factors, such as iron [49], have also been reported to mediate the in vitro anti-Pb activity of macrophages. Thus the precise mechanisms of $P$. brasiliensis killing by these phagocytes have not yet been fully elucidated, since the identification of the cytotoxic molecules that are released in vivo and that account for the killing of $\mathrm{Pb}$ has not been accomplished likewise. On the other hand, lack of adequate cytoplasmatic acidification in macrophages of chronic form PCM patients has recently been reported and may suggest a possible evasion mechanism [50].

A series of immunohystochemical studies of patients' lesions revealed findings that were consistent with the in vitro observations. Well-organized granulomas were associated with Th-1 like profile of cytokine expression (preferential expression of IFN- $\gamma$ over IL-10 and IL-5), while poorly organized granulomas presented the inverse pattern [39]. TNF- $\alpha$ was equally expressed in the two types of granulomatous reactions. Another study showed that TNF- $\alpha$ and 
TGF- $\beta 1$ were highly and diffusely expressed in lesions from patients with chronic form of the disease before treatment. After 20 days of anti-fungal treatment, TNF- $\alpha$ expression was substantially decreased, while TGF- $\beta 1$ remained highly expressed, now as deposits associated with areas of fibrosis [19]. However, no direct association with the number or morphological aspect of the yeast cells within the lesions was described in these studies. A third study also included biopsies of inflamed lymph nodes from patients with the acute form of the disease. These biopsies showed higher counts of yeast cells compared to the oral mucosa biopsies of chronic form lesions [38]. Inducible nitric oxide synthase, an enzyme involved with the production of NO, was expressed at low levels in the lesions, suggesting that this cytotoxic agent may have a role in human host defense against $\mathrm{Pb}$. These low levels of expression would be due to the high expression of anti-inflammatory cytokines (TGF- $\beta$ and IL-10) and low TNF- $\alpha$ expression in the lesions, and would represent a mechanism of escape of the fungus. The role of NO in PCM remains controversial [51]. Interestingly, all three studies described areas with purulent exudates, probably representing failure of the local host's immune responses in containing the yeast.

\section{Modifying the immune responses?}

Overall, these studies report on the events underlying the patterns of immune responses associated with the different outcomes of the host-parasite interaction in PCM. However, most were mainly descriptive studies. Few attempted to modulate these events, e.g., either by replacing cytokines or by blocking their action by the addition of neutralizing antibodies, in order to verify their actual role in the regulation of the host-parasite interaction in patients, and in establishing the hierarchy among them. In this regard, we showed a few years ago that IL-10 has a major role in the down modulation of the Th-1 immune responses. Blockade of IL-10 could in vitro redress the gp43-induced IFN- $\gamma$ release of patients with severe, untreated disease [52]. INF- $\gamma$ is considered a critical cytokine in anti-Pb immunity, at least in experimental models of PCM [53]. Concomitant addition of rhIL-12 optimized the beneficial effects. Neutralization of IL-10 per se resulted in enhanced release of IL-12p70 to levels comparable with those of healthy $\mathrm{Pb}$-sensitized controls, and almost normalization of the expression of the $\beta 2$ subunit of the IL-12 receptor on T-cells, thereby re-establishing the integrity of the IL-12/INF- $\gamma$ pathway [54]. In this regard, development of severe disseminated subacute PCM was reported in a boy with defective IL-12/IFN$\gamma$ pathway due to a point mutation in the $\beta 1$ subunit of the IL-12 receptor, highlighting the importance of this pathway for the integrity of the host defense against $P$. brasiliensis. [55]. IL-10, but not TGF- $\beta$ was able to decrease the phagocytic and fungicidal activity of macrophages from healthy donors against $\mathrm{Pb}$ [56]. Thus IL-10 seems to be the major dominant negative cytokine in PCM patients, blocking the full expression of immunity mediated by the IFN- $\gamma / \mathrm{IL}-12$ axis and the fungicidal activity of macrophages. Other studies have shown that TNF- $\alpha$ was the most potent agonist of $\mathrm{Pb}$ fungicidal activity by macrophages from both healthy donors and patients, provided the cells have been pre-activated with IFN- $\gamma$ [31]. GM-CSF as well was able to increase the fungicidal activity of human macrophages [57], while prostaglandins were shown to strongly inhibit it [46]. Treatment of healthy donors' macrophages solely with IFN- $\gamma$ induced restriction of intracellular $\mathrm{Pb}$ multiplication, but killing was not evidenced [58]. High levels $(1,000 \mathrm{U} / \mathrm{ml})$ of IFN- $\gamma$ only modestly increased the in vitro fungicidal activity of patients' macrophages $(<30 \%$ reduction in $\mathrm{CFU})$ against a virulent strain as compared to $\sim 50 \%$ reduction in CFU of an avirulent strain [31]; in this regard, much lower amounts $(250 \mathrm{U} / \mathrm{ml})$ of IFN- $\gamma$ were able to enhance the fungicidal activity against $C$. albicans yeast cells (to $\sim 40 \%$ reduction) [31]. Thus, the virulent phenotype in $\mathrm{Pb}$ would apparently be associated with higher resistance to macrophage killing.

The discovery that cytokine programming of the immune responses is mediated by a family of intracellular signaling factors, the protein tyrosine kinases, known as Janus kinase (JAK), and the signal transducer and activator of transcription (STAT) molecules, over 15 years ago, has come up with new potential targets for the pharmaceutical modulation of the immune responses [59]. This family comprises four JAKs molecules (JAK1 to 3, and Tyk-2) and seven STAT molecules (STAT1 to 6, including STAT5A and STAT5B). Distinct STATs are coupled to different cytokine signaling, thus some selectivity 
may be achieved when these proteins are modulated pharmacologically. While STAT-6 phosphorylation is induced by IL-4 and IL-13, being critical to Th-2 type responses development, STAT4 phosphorylation is related to the IL-12/IFN- $\gamma$ pathway, being critical to development of Th-1 type responses [60]. STAT3 in turn, seems essential for the transduction of IL-10 inhibitory signals [61]. These molecular targets are particularly attractive because of their intracellular localization, selective tissue expression, and, depending on the molecule, discrete functions [62]. They have the potential to improve therapeutic benefits compared to traditional drugs or systemic neutralization of cytokines. Our laboratory is currently studying the patterns of activation of some STATs in response to gp43 of PCM patients. We found that patients' T-cells respond to gp43 by significantly upregulating the expression of both active and inactive STAT3 compared to cured controls, but by down regulating the expression of both STAT1 and STAT4. Thus the differential pattern of STAT expression consistently reflects the well-described cytokine imbalance of PCM patients (Romano CC, Mendes-Giannini MJS, Benard $\mathrm{G}$, unpublished data). STAT5 expression was also increased in patients' cells, but the meaning of this finding is less clear. These data illustrate the potential of using STATS as targets for therapeutic immunodulation in this mycosis, as already proposed in other settings [62, 63]. In fact, the altered STAT1 and STAT4 expression in response to gp43 could be in vitro restored in patients cells with, respectively, IL-10 neutralization and rhIL-12 addition (Romano CC, Mendes-Giannini MJS, Benard G, unpublished data).

The literature has provided a large body of evidence that $\mathrm{T}$-cell costimulation is an important issue in the regulation of the immune responses in many infectious diseases [64]. Either optimal cellular immune responses or anergy and subsequent T-cell death can be elicited depending on the array of costimulatory molecules involved in the cells' crosstalking. Furthermore, better understanding of the mechanisms leading to T-cell death may offer strategies aiming to minimize cell death, and thus revert the anergic state of PCM patients. Few studies addressed this issue in PCM. IL-12, a key cytokine in driving Th-1 immune responses, was also shown to exhibit anti-apoptotic properties [65], and this mechanism may have contributed to the beneficial effects exerted by this cytokine when added to patients' PBMC cultures. Silva and coworkers have investigated the role of Fas ligand and CTLA-4 (a costimulatory molecule known to deliver down modulatory signals) [26]. Patients' T-cell apoptosis could be partly inhibited by disrupting Fas-Fas-L interactions; disruption of either Fas-FasL or CTLA-4 interactions resulted in enhancement of IFN- $\gamma$ secretion. However, the observed lack of proliferative response to $\mathrm{PHA}$ and to $\mathrm{ab}$ antigen was virtually not, or only slightly, redressed. In our laboratory, we also detected higher rates of apoptosis in gp43stimulated patients' $T$ cells as compared to cured controls' $\mathrm{T}$ cells [66]. This defect was apparently specific, since this phenomenon was not detected when a $\mathrm{Pb}$-unrelated fungal antigen was employed. In addition, attempts to revert this trend with cytokine addition also failed (Cacere CR, Mendes-Giannini MJS, Benard G, unpublished data). Thus, the mechanisms that result in the inability of patients' T-cell to exhibit adequate proliferative responses remain to be elucidated. In this regard, Silva and coworkers in an elegant study investigated the role of regulatory $\mathrm{TCD} 4^{+} \mathrm{CD} 25^{+}$cells. Such cells, expanded from patients' lesions, either inhibited or stimulated the proliferative capacity of allogeneic PBMC [67, 68]. The regulatory $\mathrm{T}$-cells derived from four chronic form patients exhibited an inhibitory capacity, while those form acute/subacute form exhibited either a stimulatory (three patients) or inhibitory (one patient) activity. Thus, it appears that different mechanisms are involved in the anergic state of chronic and acute/ subacute form patients, with the regulatory T-cells playing a suppressive role only in chronic lesions.

We also have recently investigated the expression of a number of costimulatory molecules with the hypothesis that the PCM associated T-cell anergy was due to lack of adequate costimulatory activity. Indeed, we observed enhanced expression of both CD80 and CD86 by cultured patients' monocytes $\left(\mathrm{CD} 14^{+}\right.$cells). Altered expression of these molecules has also been reported by Blotta and coworkers [33], but the connection of these findings with the altered immune reactivity of the patients remains elusive. We also detected higher expression of these molecules by T-cells from patients. In this case, it has been suggested that T-cells expressing these costimulatory molecule could interact with other T-cells expressing their natural ligands, CD28 and CTLA-4, resulting in 
an immunosuppressive loop [69]. This hypothesis seemed attractive because Silva's group [26] and we found enhanced expression of CTLA-4 in patients' T-cells. We then tested this hypothesis by blocking the signaling via CD80, CD86, or CTLA-4 in PBMC with the respective neutralizing antibodies and examining the gp43-elicited proliferative responses in these conditions. These treatments were unable to revert the antigen-specific T-cell anergy (Cacere CR Mendes-Giannini MJS, Benard G, unpublished data). The newly described costimulatory molecules, ICOS and PD-1 [65, 70], were also increasingly expressed by patients' T-cells, but again our preliminary data suggest that blockade of the respective signaling pathways with anti-ICOS or anti-PD-1, PDL-1, PDL-2 MoAbs was ineffective (Cacere CR MendesGiannini MJS, Benard G, unpublished data). We are currently determining the apoptotic pathways triggered in PCM patients' T cells, either the extrinsic pathway (mediated by caspase 8 activation) or the intrinsic one (mediated by caspase 9 activation). Preliminary ex vivo data show that both pathways would be active in the T-cells. Our current hypothesis is that $\mathrm{Pb}$-antigens reactive $\mathrm{T}$-cells in patients with PCM would be committed to death due to exposure to fungal antigens in the context of inadequate costimulation, and that this commitment would be refractory to further attempts of in vitro modulation. A similar hypothesis has been previously postulated by other investigators [51].

Finally, as the historical gap between the innate and adaptive immunities has become increasingly narrower, many studies have focused on the biology of dendritic cells and its influence on the adaptive immune responses in several inflammatory conditions. The published data on the participation of these cells in PCM is almost exclusively based on experimental PCM. We have recently addressed this issue in PCM patients. Our preliminary data show decreased phagocytic activity by patients' DC compared to healthy donors (Baida $\mathrm{H}$, Romano $\mathrm{CC}$, Mendes-Giannini MJS, unpublished data). This was associated with an altered pattern of expression of several costimulatory molecules and the low capacity of these cells to induce gp43-specific T-cell proliferative response. On the other hand, these $\mathrm{DC}$ were able to release higher amounts of IL-12p70 and TNF- $\alpha$ after challenge with gp43 than controls (Baida $\mathrm{H}$, Romano CC, Mendes-Giannini MJS, unpublished data). Thus, DC from PCM patients may contribute to the inflammatory response by secreting proinflammatory cytokines, but would be unable to present $\mathrm{Pb}$-specific antigens to T-cells.

Some groups have directed their efforts at the study of human T-cell recognition of, and reactivity to, peptides derived from the main diagnostic antigen of $\mathrm{Pb}, \mathrm{gp} 43$, aiming to select the most immunogenic peptides that would be potentially useful in the design of vaccines against PCM. These studies were based on the encouraging results obtained using this strategy in experimental PCM [71]. Although reactivity to individual peptides was low, both in terms of proportion of responders (usually $\leq 50 \%$ ) and stimulation index levels (frequently $\leq 4$ ) [72, 73], some were more promiscuous. Evaluations of the cytokines potentially elicited by these peptides are needed to better define their antigenic capacity. In this regard, a recent report described the kinetics of the secretion of some cytokines in response to mixtures of gp43 peptides by cells from patients cured of PCM. There was considerable variability both in the patients' secretion levels and in secretion kinetics among the cytokines [74]. Peptide pools combining these peptides may represent a better alternative [73], but this awaits further studies. Nevertheless, a debate among clinicians, public health planners, and immunologists about the real need for prophylactic and/or preventive measures, as well as on the most adequate strategies to implement them, has never taken place. So far, a therapeutic vaccine may possibly more useful or feasible than a prophylactic one. Moreover, the mechanisms of susceptibility to PCM that could help in the definition of the target population are still unknown. In this regard, early studies have reported an association between certain HLA alleles and susceptibility to PCM [75-77]. This was not further confirmed by more recent studies [78, 79]. However, Shikanai-Yasuda's group has recently suggested that the class II allele DRB $1 * 11$ was associated with the less severe, chronic unifocal form of the mycosis, thus suggesting that this allele may confer some resistance against $\mathrm{Pb}$ dissemination [80]. A study on the frequency of a single nucleotide gene polymorphism in the IL-10 and TNF- $\alpha$ genes in a relatively small number of individuals with and without PCM has recently been released [81]. Clearly, more studies are needed to addressing the issue of which population would benefit more from prophylactic or 
preventive measures, in view of the very low disease/ infection ratio. As already stated by some investigators [82], we still believe that the current best approach still is an early diagnosis.

\section{Concluding remarks}

Although the literature on the immunopathology of human PCM has progressed notably, with a substantial increase in the number of published articles, the overall picture of what are the mechanisms of susceptibility or resistance continues to be fragmentary. As a consequence, the benefits of this improved knowledge did not yet reach clinical practice. I would say that we are facing a puzzle with an increasing number of pieces to assembly, and some of these pieces seem not to fit. Thus we are still far from having answers to the questions raised in the beginning of this article. We certainly have made progresses in the understanding of the events that characterize the different outcomes of the hostparasite interaction. However, we are still far from the knowledge that could allow us to design immunological tools that could favorably modulate the immune response of the patients and abbreviate the time of treatment, and consequently prevent the development of sequels. Fortunately, the previous view of the immune system, as having two almost independent arms, the innate and adaptive immunity, leaving a large gap between them, is now being overcome. Immunologists are now trying to dissect the connections between these two arms, narrowing this gap. This will certainly result in more productive results that may clarify the mechanisms associated with susceptibility and resistance to disease development. We are currently investigating the innate immunity events that trigger the IL-12/IFN- $\gamma$ axis conferring protection to PCM in those individuals living in endemic areas who have been infected, but did not develop the mycosis.

With this in mind, immunological investigation should address the following critical points:

We still do not know what in the host immune response has failed in those few who develop the acute/subacute form of the disease. This defect must be, at one side, sharp enough, because the cellular immune responses to $\mathrm{Pb}$ antigens of these patients are profoundly depressed and the yeast dissemination usually causes an overwhelming disease, on the other side it is subtle enough in that it does not render such patients prone to other infectious illnesses. In this regard, recent studies described apparently "usual" TB in persons without predisposition to other unusual infectious diseases that was, in fact, associated with inborn defects in the IFN- $\gamma / \mathrm{IL}-12$ pathway of these persons [83, 84]. These studies have led to the speculation that conventional $\mathrm{TB}$, and perhaps other endemic diseases that affect only a small proportion of the infected population, may be due to subtle, yet unexplored, defect in this or other immunological pathway. Alternatively, this clinical presentation might be due to particularly virulent strains. Cellular and molecular biology studies are now beginning to address the putative mechanisms and molecules associated with the variability in virulence among $\mathrm{Pb}$ strains (up to now studied only in animal models of PCM) [85-88]. The few attempts of connecting $\mathrm{Pb}$ components (e.g., 1,3-alpha glucan) with the virulence trait have failed [89].

The same holds true with respect to the mechanisms that disturb the apparently clinically silent equilibrium between host and parasite that have lasted for many years, sometime decades, and which led to the progressive development of the chronic form of the disease.

Finally, one additional important topic that has been largely overlooked is the study of mechanisms that lead to development of fibrosis. This represents one of the major concerns for those who deal with PCM patients.

In any case, the focus should preferentially be put in the connection between the innate and adaptive immunities.

Acknowledgments I would like to acknowledge Carla C Romano, Camila R Cacere, Heide Baida, and Soraya Ogusuku for their dedicated contribution to the studies on PCM, Maria José Soares Mendes-Giannini for the continuous collaborative work, Luís A Fonseca for the critical reading of the manuscript, and Prof. Alberto JS Duarte and the staff of the LIM-56 for their support. Work partially supported by FAPESP, CNPq and LIM-HC. GB is as senior researcher from CNPq.

\section{References}

1. Rippon JW. The pathogenic fungi and the pathogenic actinomycetes. 3rd ed. Saunders: Philadelphia; 1988. p. 797. 
2. Enarson DA, Rouillon A. The epidemiological basis of tuberculosis control. In: Davies PDO, editors. Clinical tuberculosis. London: Champman \& Hall Medical; 1998. p. $35-52$.

3. Franco M, Mendes RP, Dillon NL, Mota NGS. Paracoccidioidomycosis, a recently proposed classification of its clinical forms. Rev Soc Bras Med Trop 1987;20: 129-32.

4. Benard G, Neves CP, Gryschek RCB, et al. Severe juvenile type paracoccidioidomycosis in an adult $\mathrm{J}$ Med Vet Mycol. 1995;33:67-71.

5. Benard G, Franco M. Paracoccidioidomycosis. In: Merz WG, Hay RJ, editors. Topley Wilson's medical mycology. 10th ed. London: Hodder Arnold; 2005;541-55.

6. Chikamori T, Saka S, Nagano H, et al. Paracoccidioidomycosis in Japan. Report of a case. Rev Inst Med Trop São Paulo 1984;26:267-71.

7. Lacaz CS, Faria JL, Moura RAA. Blastomicose sulamericana associada a moléstia de Hodgkin. Hospital (Rio de Janeiro) 1948;34:313-22.

8. Benard G, Duarte AJS. Paracoccidioidomycosis. A model for evaluation of the effects of human immunodeficiency virus infection on the natural history of endemic tropical diseases. Clin Infect Dis 2000;31:1032-1039.

9. Mendes NF, Musatti CC, Leão RC, MendesE, Naspitz CK. Lymphocyte cultures and skin allograft survival in patients with South American Blastomycosis. J Allerg Clin Immunol 1971;48:40-5.

10. Musatti CC, Rezkallah MT, Mendes E, et al. In vivo and in vitro evaluation of cell-mediated immunity in patients with paracoccidioidomycosis. Cell Immunol 1976;24:36578.

11. Mok PWY, Greer DL. Cell-mediated immune responses in patients with paracoccidioidomycosis. Clin Exp Immunol 1977;28:89-98.

12. Restrepo A, Restrepo M, Restrepo F, Aristizábal LH, Moncada LH, Vélez H. Immune responses in paracoccidioidomycosis. A controlled study of 16 patients before and after treatment. Sabouraundia 1978;16:151-63.

13. Arango M, Yazárbal L. T-cell dysfunction and hyperimmunoglobulinemia $\mathrm{E}$ in paracoccidioidomycosis. Mycopathologia 1982;79:115-24.

14. Costa JC, Pagnano PMG, Bechelli LM, Fiorillo AM, Filho EL. Lymphocyte transformation test in patients with paracoccidioidomycosis. Mycopathologia 1983;84:55-63.

15. Mota NGS, Rezkallah IMT, Peraçoli MT et al. Correlation between cell-mediated immunity and clinical forms of paracoccidioidomycosis. Trans R Soc Trop Med Hyg 1985;79:765-71.

16. Chequer-Bou-Habib D, Oliveira NMP, Cruz MFF Castro GB. The possible role of circulating immune complexes in the deficiency of cell-mediated immunity in paracoccidioidomycosis. Brazilian J Med Biol Res 1989;2:205-12.

17. Mota NGS, Peraçoli MTS, Mendes RRP, Gattas CR, Marques SA, Soares AMVC, Rezkallah-Iwasso MT. Mononuclear cell subsets in patients with different clinical forms of paracoccidioidomycosis. J Med Vet Mycol 1998;26:105-11.

18. Moscardi-Bacchi M, Mendes RP, Marques SA et al. In situ localization of $\mathrm{T}$ lymphocyte subsets in human paracoccidioidomycosis. J Med Vet Mycol 1989;27:149-58.
19. Parise FMR, Marques SA, Soares AMVC, et al. Cytokines released from blood monocytes and expressed in mucocutaneous lesions of patients with paracoccidioidomycosis evaluated before and during trimethoprim-sulfamethoxazole treatment. Br J Dermatol 2006;154:643-50.

20. Quagliato Jr R, de Capitani EM, Massucio RAC, Rezende $\mathrm{SM}$, Balthazar AB. The association of paracoccidioidomycosis with tuberculosis. Rev Inst Med Trop São Paulo 2005;47(suppl.):37, abstract\#05.07.

21. Benard G, Hong MA, Negro GMBD, Batista L, ShikanaiYasuda MA, Duarte AJS. Antigen-specific immunosuppression in paracoccidioidomycosis. Am J Trop Med. Hyg 1996;54:7-12.

22. Benard G, Mendes-Giannin MJS, Juvenale M, et al. Immunosuppression in paracoccidioidomycosis. $\mathrm{T}$ cell hyporesponsiveness to two Paracoccidioides brasiliensis glycoproteins that elicit strong humoral immune response. J Infect Dis 1997;175:1263-67.

23. Sugizaki MF, Peraçoli MTS, Mendes-Giannini MJS, Soares AMVC, Kurokawa CS, Mendes RP, Marques SA, Maia DVF. Correlation between antigenemia of Paracoccidioides brasiliensis, inhibiting effects of plasma in patients with paracoccidioidomycosis. Med Mycol 1999;37:277-84.

24. Diniz SN, Cisalpino PS, Koury MC, Andrade GMQ, Nogueira MGS, Goes AM. In vitro human immune reactivity of fast protein liquid chromatography fractionated Paracoccidioides brasiliensis soluble antigens. Microbes Infect 1999;1:53-360.

25. Oliveira SJ, Mamoni RL, Musatti CC, et al. Cytokines and lymphocyte proliferation in juvenile and adult forms of paracoccidioidomycosis. Comparison with infected and non-infected controls. Microbes Infect 2002;4:139-44.

26. Campanelli AP, Martins GA, Souto JT, et al. Fas-Fas Ligand (CD95-CD95L) and cytotoxic T lymphocyte antigen-4 engagement mediate $\mathrm{T}$ cell unresponsiveness in patients with paracoccidoidomycosis. J Infect Dis 2003;187:505-1496.

27. Karhawi AS, Colombo AL, Salomão R. Production of IFNgamma is impaired in patients with paracoccidioidomycosis during active disease and is restored after clinical remission Med Mycol 2000;38:225-9.

28. Benard G, Romano CC, Cacere CR. et al. Imbalance of IL2, IFN-gamma and IL-10 secretion in the immunosuppression associated with human paracoccidioidomycosis. Cytokine 2001;13:248-52.

29. Mello LM, Vergara MLS, Rodrigues Júnior V. Patients with active infection with Paracoccidioides brasiliensis immune response characterized by high interleukin 4 and interleukin 5 production. Hum Immunol 2002;63:149-54.

30. Fornazim MC, Balthazar A, Quagliato R Jr et al. Evaluation of bronchoalveolar cells in pulmonary paracoccidioidomycosis. Eur Respir J 2003;22:895-9.

31. Calvi SA, Soares AM, Peraçoli MT, Mendes RP, et al. Effect of cytokines on the in vitro fungicidal activity of monocytes from paracoccidioidomycosis patients. Microbes Infect. 2003;5:107-13.

32. Peraçoli MT, Kurokawa CS, Calvi SA, et al. Production of pro-and anti-inflammatory cytokines by monocytes from patients with paracoccidioidomycosis. Microbes Infect 2003;5:8-13. 
33. Mamoni RL, Blotta MHSL. Kinetics of citokines and chemokines gene expression distinguishes Paracoccidioides brasiliensis infection from disease. Cytokine 2005;32:20-9.

34. Mamoni RL, Blotta MHSL. Flow-cytometric analysis of cytokine production in human paracoccidiodomycosis. Cytokine 2006;35:207-16.

35. Ferreira KS, Almeida SR Immunization of susceptible mice with gp43-pulsed dendritic cells induces an increase of pulmonary Paracoccidioidomycosis. Immunol Lett 2006;103:121-6.

36. Franco M. Host-parasite relationships in paracoccioidomycosis. J Med Vet Mycol 1986;25:5-18.

37. Sandoval MBT Sotto MN, de Brito T. Antigen distribution in mucocutaneous biopsies of human paracoccidioidomycosis. Int J Surg Pathol 1996;3:181-8.

38. Neworal EPM, Altemani A Mamoni RL, Noronha IL, Blotta MHSL. Immunocytochemical localization of cytokines and inducible nitric oxide synthase (INOS) in oral mucosa and lymph nodes of patients with paracoccidiodomycosis. Cytokine 2003;21:234-41.

39. Pagliari C, Sotto MN, et al. Dendritic cells and pattern of cytokines in paracoccidioidomycosis skin lesions. Am J Dermatopathol 2003;25:107-12.

40. Burger E, Vaz CC, Sano A, Calich VL, Singer LMV, Xidiel CF, Kashima SS, Nishimura K, Miyaji M. Paracoccidioides brasiliensis infection in nude mice: studies with isolates differing in virulence and definition of their $\mathrm{T}$ cell-dependent and T cell independent components. Am J Trop Med Hyg 1996;55:8-391.

41. Kurita N, Oarada M, Brummer E, et al. Fungicidal activity of human peripheral blood leukocytes Paracoccidioides brasiliensis yeast cells. Med Mycol 2005;43:22-417.

42. Kurita N, Oarada M, Miyaji M, et al. Effect of cytokines on antifungal activity of human polymorphonuclear leucocytes against yeast cells of Paracoccidioides brasiliensis Med Mycol 2000;38:177-82.

43. Rodriguez DR, Dias MLA, Calvi SA, Peracoli MT, Soares AM. Paracoccidioides brasilienses killing by IFN-gamma, TNF-alpha and GM-CSF activated human neutrophils: role for oxygen metabolites. Med Mycol 2007;45:27-33.

44. Goihman-Yahr M, Albornoz MC, Yarzábal L, Gómez MH, Martín BS, Ocanto A, Gil F, Convit J. Defect of in vitro digestive ability of polymorphonuclear leukocytes in paracoccidioidomycosis. Infect Immun, 1980;48:557-66.

45. Corvino CL, Mamoni RL, Fagundes GZ, Blotta MH. Serum interleukin 18 and soluble tumor necrosis factor receptor 2 are associated with disease severity in patients with paracoccidioidomycosis. Clin Exp Immunol 2007;147:90-483.

46. Soares AMVC, Calvi SA, Peraçoli MTS, Fernandez AC, Dias LA, Anjos AR. Modulatory effect of prostaglandins on human monocyte activation for killing of high and low virulence strains of Paracoccidioides brasiliensis. Immunology 2001;102:480-5.

47. Carmo JPM, Dias MLA, Calvi SA, Peraçoli MTS, Soares AMVC. TNF- $\alpha$ activates human monocytes for Paracoccidioides brasiliensis killing by an $\mathrm{H}_{2} \mathrm{O}_{2}$ dependent mechanism. Med Mycol 2006;44:363-8.

48. Bannwart CF. Efeito da interleucina-15 sobre a atividade fungicida, metabolismo oxidativo e produção de citocina por monócitos humanos, infectados in vitro com Paracoccidioides brasiliensis. MsC thesis, Faculdade de Medicina de Botucatu, Universidade Estadual Paulista "Júlio de Mesquita Filho" Botucatu, 2007.

49. Dias MLA, Calvi SA, Peracoli MT, Soares AMVC. Inhibitory effect of deferoxamine on Paracoccidioides brasiliensis survival in human monocytes: reversal by holotransferin but not by apotransferrin. Rev Inst Med Trop São Paulo 2005;47:263-6.

50. Fornari MC, Bava AJ, Guereno MT, Berardi VE, Silaf MR, Negroni R, Diez RA. High serum interleukin-10 and tumor necrosis factor alpha levels in chronic paracoccidioidomycosis. Clin Diag Lab Immunol 2001;8:1036-8.

51. Nascimento FR,Calich VL, Rodriguez D, Russo M. Dual role for nitric oxide in paracoccidioidomycosis: essential for resistance, but overproduction associated with susceptibility. J Immunol 2002;1684:593-600.

52. Romano CC, Mendes GMJS, Duarte AJS, Benard G, Mendes-Giannini MJS, Duarte AJS. IL-12 and neutralization of endogenous IL-10 revert the in vitro antigen-specific cellular immunosuppression of paracoccidioidomycosis patients. Cytokine 2002;18:57-149.

53. Souto JT, Figueiredo F, Furlanetto A, Pfeffer K, et al. Interferon-gamma and tumor necrosis factor alpha determine resistance to Paracoccidioides brasiliensis infection in mice. Am J Pathol 2000;156:20-1811.

54. Romano CC, Mendes GMJ, Duarte AJS, Benard G, et al. The role of interleukin-10 in the differential expression of interleukin-12p70 and its beta- 2 receptor on patients with active or treated paracoccidioidomycosis and healthy infected subjects Clin Immunol. 2005;114:86-94.

55. Vasconcelos DM, Grumach AS, Yamaguti A, Andrade MEB, Fieschi C, Beaucoudre L, Casanova JL, Duarte AJS. Paracoccidioides brasiliensis disseminated disease in a patient with inherited deficiency in the $\beta 1$ subunit of the Interleukin (IL)-12/IL23 receptor. Clin Inf Dis 2005;41:31-7.

56. Soares AMVC, Silva WB, Rodrigues DR, Calvi SA, Peraçoli MTS, Kurokawa CS. IL-10 but not TGF-beta inhibits Paracoccidioides brasilensis killing by human activated monocytes. Ann Rev Biomed Sci- Special Issue 2002; 4:89.

57. Soares AMVC, Carmo JP, Peraçoli MTS S A, Dias LA, Tavian EG. Role of granulocyte macrophage colony simulating factor (GM-CSF) on human monocytes activation in vitro for high virulent Pacoccidioides brasiliensis killing. Ann Rev Biomed Sci- Special Issue 2002;4:94.

58. Bacchi MM, Brummer E Stevens DA. Support of Paracoccidioides brasiliensis multiplication by human monocytes or macrophages: inhibition by activated phagocytes. $\mathbf{J}$ Med Microbiol 1994;40:159-64.

59. Chen W, Hershey GKKH. Signal transducer and activator of transcription signals in allergic disease. J Allergy Clin Immunol 2007;119:529-41.

60. Levy DE, Darnell Jr JE. Transcriptional control and biological impact. Nat Rev Mol Cell Biol 2002;3:651-62.

61. Lang R. Tunning of macrophage responses by STAT3inducing cytokines: molecular mechanisms and consequences in infection. Immunobiology 2005;210:63-76.

62. Shea JJO, Park H, Pesu M, Borie D, Changelian P. New strategies for immunosuppression: interfering with 
cytokines by targeting the Jak/Stat pathway. Cur Opin Rheumatol 200;17:305-11.

63. Popescu FD. New asthma drugs acting on gene expression. J Cell Mol Med 2003;7:475-86.

64. Chen LW. Co-signaling molecules of the B7- CD28 family in positive and negative regulation of $\mathrm{T}$ lymphocytes response. Microbes Infect 2004;6:759-66.

65. Marth T, Strober W, Kelsall BL. High dose tolerance in ovalbumine TCR-transgenic mice. Systemic neutralization of IL-12 augments TGF- $\beta$ secretion and T cell apoptosis. J Immunol 1996;157:2348-57.

66. Cacere CR, Romano CC, Mendes-Giannini MJS, Duarte AJS, Benard G. The role of apoptosis in the antigen-specific T-cell hyporesponsiveness of paracoccidioidomycosis patients. Clin Immunol 2002;105:215-22.

67. Cavassani KA, Campanelli AP, Moreira AP et al. Systemic and local characterization of regulatory $\mathrm{T}$ cells in a chronic fungal infection in humans. J Immunol 2006;177:5811-8.

68. Cavassani KA. Participação de células TCD4CD25 regulatórias (Tregs) no controle da resposta imune durante a paracoccidioidomicose humana. PhD Thesis, Faculdade de Medicina de Ribeirão Preto, University of São Paulo, Brazil, 2006.

69. Von Boehmer H. Mechanisms of suppression by suppressor T cells. Nat Immunol 2005;6:44-338.

70. Freeman GJ, Long AJ, Bourque Y, Chernova T, et al. Engagement of the PD-1 immunoinhibitor receptor by a novel B7 family member leads to negative regulation of lymphocyte activation. J Exp Med 2000;192:1027-34.

71. Taborda CP, Juliano MA, Puccia R, Franco M, Travassos LR. Mapping of the T-cell epitope in the major 43 kilodalton glycoprotein of Paracoccidioides brasilliensis which induces a Th-1 response protective against fungal infection in Balb/c mice. Infect Immun 1998;66:786-93.

72. Iwai LK, Yoshida M, Shikanai-Yasuda MA, Goldberg AC, Juliano MA, Juliani L, Sette A, Kalil J, Cunha NE, Travassos LR. In silico prediction of peptides binding to multiple HLA-DR molecules accurately identifies immunodominant epitopes from gp43 of Paracoccidioides brasiliensis frequently recognized in primary peripheral blood mononuclear cell responses from sensitized individuals. Mol Med 2003;9:19-209.

73. Iwai LK, Yoshida M, Sadahiro A, Marin LM, Goldberg AC, Juliano MA, Juliano L, Shikanai-Yasuda MA, Kalil J, Neto EC, Travassos LR. T-Cell recognition of Paracocciodioides brasiliensis GP43-derived peptides in patients with paracoccidioidomycosis and healthy individuals. Clin Vac Immunol 2007;14:474-6.

74. Sadahiro AS, Diogo CL, Oshiro TM, Shikanai-Yasuda MA. Kinetics of IFN-gamma, TNF-alpha, IL-10 and IL-4 production by mononuclear cells stimulated with gp43 peptides, in patients cured of paracoccidioidomycosis. Rev Soc Bras Med Trop 2007;40:156-62.

75. Restrepo FM, Restrepo M, Restrepo A. Blood groups and HLA antigens in paracoccidioidomycosis. Sabouraudia 1983;21:35-9.

76. Lacerda GB, Arce GB, Telles Filho FQ. Increased frequency of HLA-B40 in patients with paracoccidioidomycosis. J Med Vet Mycol 1988;26:253-256.
77. Goldani LZ, Monteiro CM, Donadi EA, Martinez R, Voltarelli JC. HLA antigens in Brazilian patients with paracoccidioidomycosis. Mycopathologia 1991;114:8991.

78. Rebellato CLK. Estudo da associação entre antígenos HLA-A, B, C, DR e DQ e a paracoccidiodomicose infecção e a forma crônica da paracoccidioidomicose doença. PhD thesis, Universidade Federal do Paraná, 1996.

79. Dias MF, Pereira AC, Pereira A, Alves MS. The role of HLA antigens in the development of paracoccidioidomycosis. J Eur Acad Dermatol Venereol 2000;14:166-71.

80. Sadahiro A, Roque AC, Shikanai YMA. Generic human leukocyte antigen class II (DRB1 and QB1) alleles in patients with paracoccidioidomycosis. Med Mycol 2007;45:35-40.

81. Bozzi A, Pereira PPN, Reis BS, Goulart MI, Pereira MCN, Pedroso EP, Leite MF, Goes AM. Interleukin-10 and tumor necrosis factor- $\alpha$ single nucleotide gene polymorphism frequency in paracoccidioidomycosis. Hum Immunol, 2006;67:931-9.

82. Tobon AM, Agudelo CA, Osorio ML, Alvarez DI, Arango M, Cano LE, Restrepo A. Residual pulmonary abnormalities in adult patients with chronic paracoccodioidomycosis prolonged follow up after itraconazole therapy. Clin Infect Dis 2003;7:898-904.

83. Jouanguy E, Cherradi SL, Fondanèche MC, Tuerlinckx D, Blanche S, Emile JF, Gaillard JL, Schreiber R Levin M, Fischer A Hivroz C, Casanova JL. Partial Interferon- $\gamma$ receptor 1 deficiency in a child with tuberculoid bacillus Calmette-Guérin infection and a sibling with clinical tuberculosis. J Clin Invest 1997;11:2658-64.

84. Akahoshi M, Nakashima H, Miyake K, InoueY, Shimizu S, TanakaY, Okada K, Otsuka T, Harada M. Influence of interleukin-12 receptor beta 1 polymorphisms on tuberculosis. Hum Genet 2003;12:43-237.

85. Campos MCRM, Gesztesi JL, Vincentini AP, Lopes JD, Camargo ZP. Expression aond isoforms of GP43 in different strains of Paracoccidioides brasilensis. J Med Vet Mycol 1995;33:223-7.

86. Barbosa HF, Montenegro MR, Bagagli E. Virulence profiles of ten Paracoccidioides brasilensis isolates obtained from armadillos (Dasypus novemcinctus). Med Mycol 2003;41:89-96.

87. Carvalho KC, Ganiko LBWL, Morais FV, Marques ER, Goldman GH, Franco MF, Puccia R. Virulence of paracoccioidioides brasiliensis and GP43 expression in isolates bearing known PbGP43 genotype. Microbes Infect 2005; 7:55-65.

88. Kurokawa CS, Lopes CR, Sugizaki MF, Kuramae EE, Franco MF Peraçoli MTS. Virulence profile of ten Paracoccidioides brasiliensis isolates. Association with morphologic and genetic patterns. Rev Inst Med Trop S Paulo 2005, 47:257-62.

89. Zacharias D, Ueda A, Moscardi BM, Franco M, San BG. A comparative histopathological, immunological, and biochemical study of experimental intravenous paracoccidioidomycosis induced in mice by three Paracoccidioides brasiliensis isolates. J Med Vet Mycol 1986;24:445-54. 